\title{
Telerheumatology and its interplay with patient-initiated care
}

\author{
Arpit Mago $^{1} \cdot$ Vikas Aggarwal $^{2} \cdot$ Latika Gupta $^{2}$ (i)
}

Received: 28 May 2021 / Accepted: 19 June 2021 / Published online: 24 June 2021

(c) The Author(s), under exclusive licence to Springer-Verlag GmbH Germany, part of Springer Nature 2021

The ongoing COVID-19 pandemic has ushered in an era of rapid digitalization of medicine, ranging from Teleconsultations amid widespread lockdowns, to remote monitoring using smartphone apps, wearables, and patient-reported outcome measures (PROMs) [1]. Bioinformatics approaches to analyze time stamped and geo-sensed tweets and APIs (Application Programming Interfaces) have led researchers to predict the occurrence of local outbreaks for timely action and resource mobilization [2,3]. The rapid shifts have only led researchers and data scientists all the more excited to see the massive emerging databank for AI-based analysis and automation of healthcare systems. These data banks may also support the vision for precision medicine-driven individualized healthcare.

The pandemic has forced physicians worldwide to rapidly adapt and move to objective means of remote assessment. An exponential increase in recent literature on approaches for remote assessment testifies to this remarkable shift in healthcare. In the words of R Wootton and R Bonnardot, "We expect that teleconsultations will become so common as to be unremarkable, that the prefix tele-will disappear, and that all telemedicine work will be considered as part of usual practice" [4].Travel cost, time and effort are another determinant of overall patient quality and life.

The diagnoses of most of the rheumatologic diseases (RDs) entail a chronic course and the need for lifelong monitoring and hospital visits [5]. This only adds to the existent ginormous burden of the healthcare system, more so in developing countries like India with meagre funds for healthcare, particularly in strained times of a raging global pandemic. Today it is integral for a rheumatologist to integrate immunology with disease pathogenesis, infectious

Latika Gupta

drlatikagupta@gmail.com

Jawaharlal Nehru Medical College, Belgaum, India

2 Department of Clinical Immunology and Rheumatology, Sanjay Gandhi Postgraduate Institute of Medical Sciences, Lucknow, India agents, rehabilitation, public health, and epidemiology [6]. The information horizons cannot be confined to just managing immunological conditions but involve emerging, reemerging and high burden diseases. The vertical integration with various public health professionals by networking and digitalization will usher in a new era of integrated medicine.

Handing patients, the baton for self-care, monitoring, and self-sampling as suggested by Morf $\mathrm{H}$ et al. may be the way forward to share the responsibilities while moving towards a model of wholesome patient-led care [7]. Besides, an emerging plethora of patient support communities hold potential in leading a sea change in approach from hospital directed, to patient-initiated care [8]. Decades of research in rheumatoid arthritis has taught researchers to move away from DAS28 to MCID (Minimum clinically important difference), and patient preferences in healthcare, and control of disease activity. Patient inputs can be vital to fine-tune medications in those with minimal simmering disease activity to achieve the right balance between patient acceptable symptom state (PASS) and drug toxicity. The time has come to educate and empower our patients for meaningful care.

Such models are being explored on large scales in developed societies like Germany, where DiGA initiative is leading efforts to digitize medicine in sync with national medical systems. The new era is moving care to the patients' home, wherein patients-initiated clinics (PIC) lend autonomy to patients to consult in the ease of their natural environment while averting risks of contracting COVID-19. Digital health applications' usage during the pandemic has promoted teleconsultations with over $81.3 \%(n=243)$ of patients and $85.3 \%$ ( $n=110)$ of rheumatologists willing to skip an on face to face appointment [9]. Such models are also in sync with sustainable development goals, keeping economic, practical, and need-based assessments in mind.

Digital medicine aims to increase patient engagement by using smart apps with voice assistant features to enable even patients with arthritis to report health outcomes effectively [10]. Wearable devices would ensure more transparency between patients and healthcare providers in self-assessment and management [11]. Not only do they help in effective 
recording of patient prognosis but also endure new habits, turning external motivations into internal ones. Furthermore, wearables enhance physical activity as a behavior change technique [12]. The results of a systematic review using wearable activity tracker reported positive outcomes showing an increase of over 1520 steps per day compared with a group of patients not using trackers[13].

Tools such as the Internet arthritis self-management help patients design personalized exercise schedules, provide medical advice as well as demonstrate useful exercises that can be followed by patients with arthritis. The mind is the driver of physical health-and integrating cognitive assessments and psychometrics with Telehealth services hold immense potential in improving patient care.

While we may still be far away from diagnosis over Teleconsults, remote monitoring is feasible, and it may allow for early sustainable, and pragmatic interventions and prescriptions of medications for wholesome care [14]. However, social, linguistic and cultural barriers may continue to impede large-scale acceptance of such initiatives in the third world. Understanding physician and patient barriers specific to local practice may provide vital insights to support administrators while enabling widespread use of technologyassisted healthcare for better penetration to the countryside. While patient-initiated research registries are still new, we hope that rapid digitalization would facilitate and empower and involve both the patients and rheumatologists as equal stakeholders in management as well as research. This work highlights the positive interplay between digital health and patient-initiated care.

Author contributions All authors were involved in manuscript ideation and preparation.

Funding No funding was received.

\section{Declarations}

Conflict of interest The authors have nothing to disclose.

\section{References}

1. Naveen R, Sundaram TG, Agarwal V, Gupta L (2021) Teleconsultation experience with the idiopathic inflammatory myopathies: a prospective observational cohort study during the COVID-19 pandemic. Rheumatol Int 41(1):67-76. https://doi.org/10.1007/ s00296-020-04737-8

2. Han X, Wang J, Zhang M, Wang X (2020) Using social media to mine and analyze public opinion related to COVID-19 in China. Int J Environ Res Public Health 17(8):2788. https://doi.org/10. 3390/ijerph17082788

3. Goel A, Gupta L (2020) Social media in the times of COVID-19. J Clin Rheumatol Pract Rep Rheum Musculoskelet Dis 26(6):220 223. https://doi.org/10.1097/RHU.0000000000001508

4. Wootton R, Bonnardot L (2015) Telemedicine in low-resource settings. Front Public Health 3:3. https://doi.org/10.3389/fpubh. 2015.00003

5. McWilliam CL (2009) Patients, persons or partners? Involving those with chronic disease in their care. Chronic Illn 5(4):277292. https://doi.org/10.1177/1742395309349315

6. Misra DP, Agarwal V, Gasparyan AY, Zimba O (2020) Rheumatologists' perspective on coronavirus disease 19 (COVID-19) and potential therapeutic targets. Clin Rheumatol 39(7):2055-2062. https://doi.org/10.1007/s10067-020-05073-97

7. Morf H, Krusche M, Knitza J (2021) Patient self-sampling: a cornerstone of future rheumatology care? Rheumatol Int 41(6):11871188. https://doi.org/10.1007/s00296-021-04853-z

8. Gupta L, Gadiwala SF (2021) Coping with the coronavirus disease-2019 pandemic: a giant leap towards digital transformation in academic research. Indian J Rheumatol. https://doi.org/10.4103/ injr.injr_251_20

9. Kernder A, Morf H, Klemm P, Vossen D, Haase I, Mucke J, Meyer M, Kleyer A, Sewerin P, Bendzuck G, Eis S, Knitza J, Krusche M (2021) Digital rheumatology in the era of COVID-19: results of a national patient and physician survey. RMD Open 7(1):e001548. https://doi.org/10.1136/rmdopen-2020-001548

10. Solomon DH, Rudin RS (2020) Resear2020. Retrieved from: https://www.nature.com/articles/s41584-020-0461-x. Digital health technologies: opportunities and challenges in rheumatology. Nat Rev Rheumatol 16(9): 525-535. doi:https://doi.org/10. 1038/s41584-020-0461-x. Accessed 20 May 2021

11. Dinh-Le C, Chuang R, Chokshi S, Mann D (2019) Wearable health technology and electronic health record integration: scoping review and future directions. JMIR mHealth uHealth 7(9):e12861. https://doi.org/10.2196/12861

12. Lyons EJ, Lewis ZH, Mayrsohn BG, Rowland JL (2014) Behavior change techniques implemented in electronic lifestyle activity monitors: a systematic content analysis. J Med Internet Res 16(8):e192. https://doi.org/10.2196/jmir.3469

13. Davergne T, Pallot A, Dechartres A, Fautrel B, Gossec L (2019) Use of wearable activity trackers to improve physical activity behavior in patients with rheumatic and musculoskeletal diseases: a systematic review and meta-analysis. Arthritis Care Res 71(6):758-767. https://doi.org/10.1002/acr.23752

14. Nune A, Iyengar K, Ahmed A, Sapkota H (2020) Challenges in delivering rheumatology care during COVID-19 pandemic. Clin Rheumatol 39(9):2817-2821. https://doi.org/10.1007/ s10067-020-05312-z

Publisher's Note Springer Nature remains neutral with regard to jurisdictional claims in published maps and institutional affiliations. 